\title{
HUBUNGAN ANTARA BERPIKIR KRITIS DAN METAKOGNITIF TERHADAP HASIL BELAJAR MAHASISWA BIOLOGI DENGAN PENERAPAN MODEL PEMBELAJARAN RWRS
}

\section{Bea Hana Siswati ${ }^{1 *}$, Slamet Hariyadi ${ }^{2}$, Aloysius Duran Corebima ${ }^{3}$}

\author{
Universitas Jember ${ }^{1,2}$, Universitas Kanjuruhan Malang ${ }^{3}$ \\ *corresponding author: beahana.fkip@unej.ac.id
}

DOI: $10.24929 /$ lensa.v10i2.110

\begin{abstract}
Abstrak
Pembelajaran daring bukan suatu alasan untuk para pendidik tidak menggunakan suatu model pembelajaran. Model pembelajaran diterapkan dengan tujuan untuk melatih kemampuan berpikir salah satunya adalah keterampilan berpikir kritis dan keterampilan metakognitif. Keterampilan abad 21 perlu dibelajarkan kepada peserta didik termasuk juga kepada mahasiswa. Penelitian ini bertujuan untuk melihat adakah hubungan antara keterampilan berpikir kritis dan keterampilan metakognitif terhadap hasil belajar mahasiswa pendidikan biologi. Metode penelitian yang digunakan ialah penelitian korelasional yang melibatkan 64 mahasiswa semester 2. Data penelitian diambil menggunakan instrumen rubrik keterampilan berpikir kritis dan keterampilan metakognitif. Data yang didapatkan dianalisis dengan bantuan software aplikasi SPSS 23. Hasil analisis data menunjukkan ada hubungan positif antara keterampilan berpikir kritis dan keterampilan metakognitif dengan hasil belajar mahasiswa dengan nilai signifikansi 0,001. Besar sumbangan relative keterampilan berpikir kritis dan keterampilan metakognitif dengan hasil belajar sebesar 21,5\%. Besar sumbangan efektif keterampilan berpikir kritis 3,5\% dan sumbangan efektif keterampilan metakognitif $18 \%$ terhadap hasil belajar mahasiswa pendidikan biologi. Adanya hubungan yang signifikan ini maka disarankan untuk para pendidik khususnya dosen mempertimbangan model RWRS agar diterapkan di pembelajaran agar mampu meningkatkan keterampilan berpikir kritis, keterampilan metakognitif dan hasil belajar mahasiswa.
\end{abstract}

Kata Kunci: Berpikir Kritis, Metakognitif, Hasil Belajar, Model Pembelajaran

\begin{abstract}
Online learning activity should not become an excuse for educators not to implement learning models in their teaching activities. Learning models are implemented to empower students' thinking skills, including critical thinking skills and metacognitive skills. Students should be equipped with the 21st century skills. This research aimed at investigating wheteher or not there was a correlation between critical thinking skills and metacognitive skills towards the learning results of Biology education students. This correlational research involved 64 second semester students. The research data were collected using the critical thinking skill rubric and metacognitive skill rubric. The collected data were analyzed using SPSS 23 application software. The results of the data analysis showed that there was a positive correlation between critical thinking skills and metacognitive skills towards learning results with a significance value of 0.001 . The relative contribution of critical thinking skills and metacognitive skills towards learning results was as much as $21.5 \%$. The effective contributions of critical thinking skills and metacognitive skills towards learning results were $3.5 \%$ and $18 \%$ respectively. Based on this results, it is recommended that the educators, especially lecturers, implement RWRS learning model in their teaching activities to improve students' critical thinking skills, metacognitive skills, and learning results.
\end{abstract}

Keywords: Critical Thinking Skills, Metacognitive Skills, Learning Results, Biology Education 


\section{PENDAHULUAN}

Perkembangan ilmu pengetahuan dan teknologi di era globalisasi memang cukup signifikan sehingga memberikan dampak yang nyata dalam dunia pendidikan. Salah satunya hadirnya pembelajaran yang bisa di lakukan dengan media online. Pendidikan jarak jauh sekarang juga semakin banyak diterapkan mengingat adanya wabah Covid-19 yang sedang melanda Indonesia dan juga dunia. Hal ini menuntut komponen pendidikan untuk siap melakukan pembelajaran model daring untuk memfasilitasi peserta didik agar tetap mendapatkan haknya untuk belajar (Aji, 2020). Lebih lanjut dijelaskan pula bahwa selama proses pembelajaran daring, sebagai pendidik diharapkan juga tetap memperhatikan berbagai keterampilan yang perlu dikuasai peserta didik. Salah satu keterampilan yang penting diberdayakan pada peserta didik adalah keterampilan berpikir kritis, keterampilan metakognitif. Serta hasil belajar peserta didik juga tidak boleh turun karena dampak dari pembelajaran daring. Oieh karena itu pemilihan proses pembelajaran selama daring juga perlu diperhatikan dengan baik.

Keterampilan berpikir kritis juga merupakan suatu keterampulan yang penting untuk diberdayakan selama proses pembelajaran. Smith \& Szymanski (2013) menyatakan bahwa dengan keterampilan berpikir kritis maka seseorang akan berhasil dalam studi dan di tempat kerja. Keterampilan berpikir kritis merupakan suatu bentuk disiplin intelektual yang secara aktif mampu membuat konsep, menerapkan, menganalisis, mengevaluasi informasi yang diperoleh dari pengalaman, observasi, refleksi, penalaran serta komunikasi (Scriven \& Paul, 2007). Peserta didik yang terbiasa menggunakan keterampilan berpikir kritis maka ia akan lebih mudah dalam menyelesaikan permasalahan di dunia nyata (Rippin, Booth, Bowie \& Jordan, 2002; Bartlett, 2002). Tempelaar (2006) menjelaskan bahwa terdapat beberapa manfaat keterampilan berpikir kritis pada diri seseorang yaitu yang pertama ia akan lebih mudah sukses dalam belajarnya dan ia mampu meningkatkan efisiensi dalam memecahkan suatu permasalahan di dunia kerja. Oleh karena itu mahasiswa perguruan tinggi harus memiliki keterampilan integratif, kemampuan bekerja dalam tim, berpikir kritis dan mewujudkan ide-idenya secara kreatif dan inovatif agar ia mampu bersaing di dunia kerja (Laberge, 2013; Eliasa, 2014).

Plotnikova \& Strukov (2019) menjelaskan bahwa pembentukan keterampilan berpikir kritis pada diri seseorang tergantung dari perubahan alamiah manusia, lingkungan sosial, dan peran dari seorang pendidik untuk membentuk keterampilan berpikir kritis peserta didiknya. Karena pembentukan berpikir kritis diperoleh dari interaksi antar pendidik dan peserta didik maka tingkat pembentukannya tergantung pada saat pembelajaran yang dilakukan. Model atau strategi pembelajaran yang diterapkan harus sesuai dan efektif dalam mendorong kemampuan berpikir kritis siswa. Sedangkan yang berkaitan dengan keterampilan metakognitif dalam pembelajaran. Brown (1983) menjelaskan bahwa metakognisi penting untuk dimiliki oleh seseorang, karena ini berhubungan dengan suatu proses merencanakan, memantau, dan mengatur pikiran dan aktivitas seseorang. Bransford et al. (1999) menjelaskan bahwa pada diri seseorang keterampilan metakognitif tidak datang dengan sendirinya tetapi ada sesuatu pendorong yang dirancang melalui suatu kegiatan instruksional. Dalam penelitian ini digunakan suatu model pembelajaran tertentu yang bisa diterapkan secara daring maupun luring. Model pembelajaran tersebut adalah model pembelajaran RWRS (Reading, Writing, Reflecting and Sharing). Model pembelajaran ini diyakini akan mampu meningkatkan keterampilan berpikir kritis, keterampilan metakognitif dan hasil belajar peserta didik. Bannert et al (2015) menjelaskan bahwa dalam penelitian yang berkaitan dengan keterampilan metakognitif diperlukan suatu strategi tertentu dalam pembelajaran sehingga mampu dengan optimal memberdayakan keterampilan metakognitif peserta didik.

Leutwyler dan Maag Merki (2009) dalam penelitiannya menjelaskan bahwa proses pembelajaran yang menedepankan suatu model pembelajaran akan mampu menciptakan iklim kelas yang mendukung proses belajar peserta didik. Selain itu suatu model tertentu yang diterapkan di kelas akan mampu membuat peserta didik 
lebih mandiri dalam belajar dan mengembangkan diri. Model pembelajaran yang diterapkan dengan optimal akan mampu meningkatkan prestasi belajar peserta didik (Muijs et al., 2014; Scheerens, 2013). Pemilihan model pembelajaran harus didasarkan pada lingkungan belajar siswa, dengan tujuan untuk meningkatkan hasil belajar peserta didik. Pembelajaran RWRS yang diterapkan pada penelitian ini termasuk dalam pembelajaran yang berasaskan pendekatan konstruktivistik. Seorang pendidik hendaknya memberikan kesempatan kepada peserta didik untuk mempraktikkan materi yang telah mereka peroleh dan pendidik bertugas untuk membimbing dan memfasilitasi belajar mereka (Joyce, Weil, \& Calhoun, 2011).

Model pembelajaran tertentu yang diimplementasikan selama proses pembelajaran akan mampu melatih keterampilan berpikir siswa, termasuk juga keterampilan metakognitif. Lin (2001) menjelaskan bahwa metakognitif bisa dimaknai lebih luas lagi yaitu terkait dengan penilaian diri, penjelasan diri, pemantauan diri, pengaturan diri terhadap proses belajar sehingga mampu meningkatkan motivasi dalam belajar. Terkait dengan hal itu, dalam penelitian ini akan mencoba mengungkap hubungan keterampilan metakognitif dengan hasil belajar. Dalam penelitiannya Zimmerman (2008), Azevedo (2009), Bannert dan Mengelkamp (2013), dan Greene dkk. (2013) mengungkap bahwa peserta didik yang mengalami kesulitan dalam menerapkan keterampilan metakognitif selama proses belajarnya maka akan cenderung mendapatkan hasil belajar yang rendah.

Dengan demikian penelitian ini diharapkan mampu memberi gambaran kepada seluruh peneliti maupun tenaga pendidik terkait pembelajaran daring yang dilakukan berdasarkan suatu model pembelajaran tertentu dan dampaknya terhadap keterampilan berpikir kritism keterampilan metakognisi, dan hasil belajar mahasiswa yang dikemas dalam penelitian korelasional. Hal ini bertujuan untuk mengungkap hubungan antara keterampilan berpikir kritis dan keterampilan metakognitif terhadap hasil belajar mahasiswa.

\section{METODE PENELITIAN}

Penelitian dilakukan dengan metode deskriptif kuantitatif studi korelasional. Variabel kriterium pada penelitian yang dilakukan adalah keterampilan berpikir kritis dan keterampilan metakognitif dan yang termasuk variabel prediktor adalah hasil belajar mahasiswa.Penelitian dilakukan pada Mata kuliah Belajar dan Pembelajaran tahun akademik 2019/2020 prodi pendidikan Biologi FKIP UNEJ. Subjek penelitian berjumlah 90 mahasiswa. Model pembelajaran yang digunakan dalam penelitian ini adalah model pembelajaran RWRS (Reading, Writing, Reflecting and Sharing). Data yang diambil berupa data keterampilan berpikir kritis, keterampilan metakognisi, hasil belajar mahasiswa. Teknik analisis data dilakukan dengan menggunakan uji hipotesis dengan bantuan program IBM SPSS Statistics 23 for Windows. Sebelum dilakukan uji hipotesis, data penelitian terlebih dahulu dilakukan uji prasyarat yaitu menggunakan Uji normalitas menggunakan Kolmogorov Smirnov test.

\section{HASIL DAN PEMBAHASAN}

Berdasarkan hasil uji normalitas yang dilakukan keterampilan berpikir kritis, keterampilan metakognitif, dan hasil belajar memiliki nilai absolute masing-masing $0.206,0.307$ dan 0.305. Dengan demikian dapat dikatakan bahwa data keterampilan berpikir kritis, keterampilan metakognitif, dan hasil belajar terdistribusi normal. Ringkasan dari hasil pengujian hipotesis dapat dilihat pada Tabel 1. Hasil Anova menunjukkan bahwa $\mathrm{F}$ hitung sebesar 8,364 dengan nilai signifikansi 0.001 kurang dari 0,05 ( $p<0,05)$. Hal tersebut menunjukkan bahwa hipotesis nol ditolak dan hipotesis alternatif diterima. Artinya, terdapat hubungan yang signifikan antara keterampilan berpikir kritis dan keterampilan metakognitif terhadap hasil belajar mahasiswa. Ringkasan hasil uji Anova hubungan antara keterampilan berpikir kritis dan keterampilan metakognitif terhadap hasil belajar mahasiswa dapat dilihat pada Tabel 1. 
Tabel 1. Uji ANOVA Hubungan antara Keterampilan Berpikir Kritis dan Keterampilan Metakognitif terhadap Hasil Belajar Mahasiswa

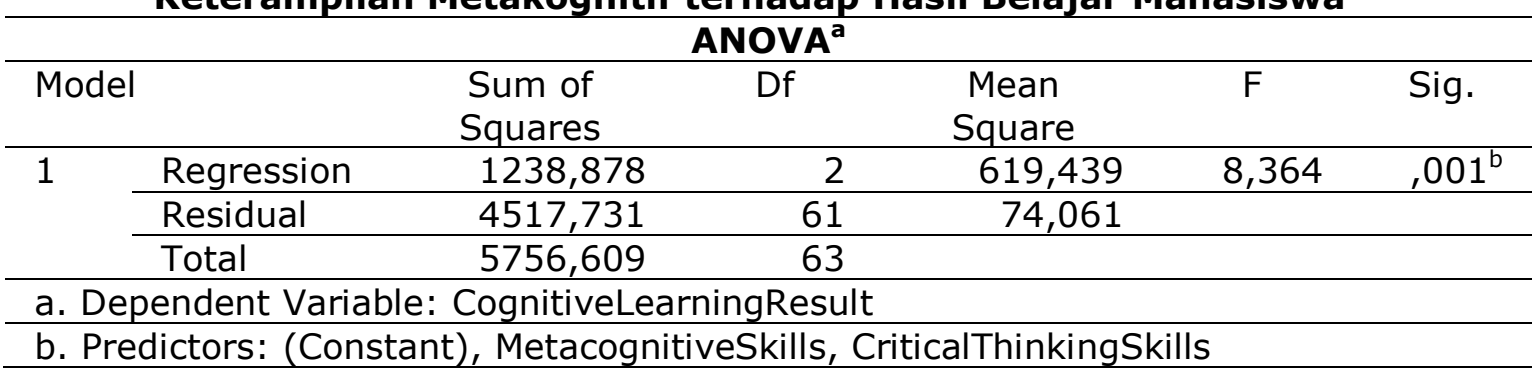

Analisis regresi digunakan untuk mengetahui korelasi antara keterampulan berpikir kritis dan keterampilan metakognitif terhadap hasil belajar mahasiswa. Selain itu, analisis regresi menunjukkan kontribusi keterampilan berpikir kritis dan keterampilan metakognitif terhadap hasil belajar mahasiswa. Ringkasan analisis regresi dapat dilihat pada Tabel 2 hingga Tabel 4.

Tabel 2. Analisis Regresi Keterampilan Berpikir Kritis dan Keterampilan Metakognitif terhadap Hasil Belajar Mahasiswa Model Summary

Model R $\quad$ R Square Adjusted R Square $\begin{gathered}\text { Std. Error of the } \\ \text { Estimate }\end{gathered}$

\begin{tabular}{lcccc}
1 &, $464^{\mathrm{a}}$ &, 215 &, 189 & 8,60588 \\
\hline a. Predictors: (Constant), MetacognitiveSkills, CriticalThinkingSkills & \\
\hline
\end{tabular}

Berdasarkan ringkasan hasil uji regresi pada Tabel 2, dapat dilihat bahwa nilai koefisien korelasi berganda $(R)$ adalah 0,464 dengan nilai determinasi $\left(R^{2}\right)$ sebesar 0,215 . Hal tersebut menunjukkan bahwa keterampilan berpikir kritis dan keterampilan metakognitif memiliki kontribusi sebesar $21,5 \%$ terhadap hasil belajar mahasiswa prodi pendidikan biologi sedangkan $78,5 \%$ dijelaskan oleh faktor lain selain keterampilan berpikir kritis dan keterampilan metakognitif.

Tabel 3 menunjukkan sumbangan relatif keterampilan berpikir kritis terhadap hasil belajar mahasiswa sebesar $16,1 \%$, dan sumbangan relatif keterampilan metakognitif terhadap hasil belajar mahasiswa adalah sebesar 83,9\%. Di sisi lain, sumbangan efektif keterampilan berpikir kritis dan keterampilan metakognitif terhadap hasil belajar mahasoswa masing-masing sebesar 3,5\% dan $18 \%$ sehingga total sumbangan efektif adalah $21,5 \%$, dan sisanya $78,5 \%$ merupakan sumbangan yang berasal dari faktor lain selain keterampilan berpikir kritis dan keterampilan metakognitif. Dengan demikian, variabel keterampilan metakognitif memiliki sumbangan yang lebih besar dibandingkan keterampilan berpikir kritis.

Tabel 3. Sumbangan Relatif dan Efektif Keterampilan Berpikir Kritis dan Keterampilan Metakognitif terhadap Hasil Belajar

\begin{tabular}{lcc}
\hline \multicolumn{1}{c}{ Variabel } & RC(\%) & EC(\%) \\
\hline X1 (K. Berpikir Kritis) & 16,1 & 3,5 \\
X2 (K. Metakognitif) & 83,9 & 18 \\
\hline Total & 100 & 21,5 \\
\hline
\end{tabular}

Tabel 4. Koefisien Persamaan Regresi Keterampilan Berpikir Kritis dan Keterampilan Metakognitif terhadap Hasil Belajar Mahasiswa Coefficients $^{\mathrm{a}}$

\begin{tabular}{|c|c|c|c|c|c|}
\hline \multirow[t]{2}{*}{ Model } & \multicolumn{2}{|c|}{$\begin{array}{l}\text { Unstandardized } \\
\text { Coefficients }\end{array}$} & $\begin{array}{c}\text { Standardized } \\
\text { Coefficients }\end{array}$ & $\mathrm{t}$ & Sig. \\
\hline & $B$ & $\begin{array}{l}\text { Std. } \\
\text { Error }\end{array}$ & Beta & & \\
\hline (Constant) & $-16,745$ & 28,842 & &,- 581 & ,564 \\
\hline
\end{tabular}




\begin{tabular}{llllll}
\hline CriticalThinkingSkills &, 450 &, 301 &, 170 & 1,497 &, 140 \\
\hline MetacognitiveSkills &, 683 &, 186 &, 418 & 3,669 &, 001 \\
\hline
\end{tabular}

a. Dependent Variable: CognitiveLearningResult

Tabel 4 menunjukkan bahwa persamaan garis regresi korelasi antara keterampilan berpikir kritis dan keterampilan metakognitif terhadap hasil belajar kognitif mahasiswa adalah $Y=-16,745+0,450 \times 1+0,683 \times 2$. Berdasarkan persamaan yang diperoleh dapat diketahui bahwa terjadi hubungan positif antara keterampilan berpikir kritis dan keterampilan metakognitif terhadap hasil belajar kognitif mahasiswa, semakin naik keterampilan berpikir kritis dan keterampilan metakognitif maka hasil belajar mereka juga semakin meningkat.

Berdasarkan hasil analisis regresi berganda diperoleh persamaan $Y=-16,745+$ $0,450 \times 1+0,683 \times 2$ dengan nilai sumbangan keterampilan berpikir kritis dan keterampilan metakognitif terhadap hasil belajar kognitif adalah sebesar $21,5 \%$. Ini menunjukkan bahwa keterampilan berpikir kritis dan keterampilan metakognitif memiliki kontribusi sebesar $21,5 \%$ dalam memberdayakan hasil belajar mahasiswa dan $78,5 \%$ dijelaskan oleh faktor lainnya selain keterampilan berpikir kritis dan keterampilan metakognitif. Nilai koefisien korelasi (R) yang di dapat adalah 0,464 yang artinya korelasi antara keterampilan berpikir kritis dan keterampilan metakognitif terhadap hasil belajar mahasiswa adalah "sedang". Penelitian ini didukung oleh penelitian sebelumnya yang mengkaji keterampilan berpikir kritis dan keterampilan metakognitif terhadap hasil belajar yaitu oleh Malahayati, dkk. (2015) dan Wicaksono (2014) yang menjelaskan ada hubungan yang positif antara keterampilan berpikir kritis dengan keterampilan metakognitif terhadap hasil belajar biologi siswa SMA di Malang.

Berdasarkan hasil analisis tersebut besarnya nilai sumbangan masing-masing prediktor terhadap kriterium pada penelitian ini diketahui bahwa keterampilan metakognitif memberikan sumbangan lebih tinggi dibandingkan keterampilan berpikir kritis. Artinya, korelasi antara keterampilan metakognitif terhadap hasil belajar mahasiswa lebih kuat dibandingkan keterampilan berpikir kritis dengan hasil belajar mahasiswa. Bae dan Kwon (2019) mengungkap bahwa peserta didik menganggap keterampilan metakognitif sebagai keterampilan yang berharga untuk dimiliki oleh seseorang. Selain itu juga bahwa keterampilan metakognitif tidak hanya bisa digunakan selama kegiatan pembelajaran tetapi juga dapat digunakan untuk kehidupan sehari-hari mereka. Banyak peserta didik yang mencoba untuk menerapkan keterampilan metakognitif dalam kehidupan sehari-hari mereka akan mampu membuat mereka menjadi individu yang mendari. Hal-hal yang mereka lakukan misalnya membuat rangkuman, mencoba strategi belajar yang berbeda, menjadi terbuka terhadap segala ide. Dengan keterampilan metakognitif siswa akan mampu memantau proses belajar dan perilaku mereka sendiri (Whitebread et al.2009).

Pada penelitian ini digunakan model pembelajaran RWRS. Model pembelajaran RWRS (Reading, Writing, Reflecting and Sharing), adalah suatu model pembelajaran yang cocok diterapkan pada saat pembelajaran daring dan memiliki tahapan-tahapan yang mampu memberdayakan kemampuan berpikir seseorang. Tahapan yang dimiliki oleh model pembelajaran RWRS adalah yang pertama Reading. Tahap Reading ini peserta didik dipaksa untuk membaca. Hal ini sejalan dengan survei PISA yang menyatakan kemampuan membaca peserta didik mengalami penurunan sejak tahun 2009 hingga 2018. Diharapkan dengan pembiasaan membaca akan membuat motivasi membaca pada diri seseorang dapat ditingkatkan. Penelitian sebelumnya telah mengungkap adanya hubungan yang signifikan antara kemampuan membaca dengan keterampilan berpikir kritis, keterampilan metakognitif dan hasil belajar peserta didik (Limbach dan Waugh, 2010, Zabit, 2010).

Tahapan yang kedua adalah Writing. Pada tahap Writing, peserta didik diminta untuk menuliskan hasil atau ringkasan atau memparafrase hasil bacaannya ke dalam kalimatnya sendiri. Peserta didik menuliskan pokok-pokok penting terkait topik yang mereka pelajari. Pada tahap ini kemampuan menulis peserta didik dilatih, harus sesuai 
dengan EYD serta kalimat yang dituliskan tersusun rapi dan bermakna. Penulisan kembali tidak terbatas dalam bentuk paragraf tetapi bisa juga dituliskan menjadi suatu peta konsep atau peta pikiran. Dalam pembelajaran, keterampilan menulis penting untuk dimiliki dan dikuasai oleh peserta didik (Saputra, 2018). Lebih lanjut dalam penelitiannya telah mengungkap adanya hubungan positif yang signifikan antara kemampuan menulis dengan kemampuan berpikir kritis. Brown (2000) menjelaskan bahwa kemampuan menulis mencerminkan pemahaman siswa terhadap materi yang telah ia pelajari. Lebih lanjut Massi (2001) mengemukakan bahwa menulis adalah alat untuk menciptakan sebuah ide dan penting pula digunakan untuk komunikasi secara interaktif.

Tahap ketiga dari model pembelajaran ini adalah Reflecting. Pada tahap ini peserta didik diminta untuk menuliskan sejauh mana mereka telah belajar tentang materi yang ia pelajari dan poin apa saja yang masih ingin mereka ketahui terkait materi tersebut, dan menemukan solusi atas permasalahan yang mereka hadapi. Dari tahap ini keterampilan metakognitif, keterampilan bagaimana ia memahami apa yang mereka pikirkan dapat terasah dengan baik. Chang (2019) menjelaskan bahwa tahap refleksi dapat bermanfaat dalam kegiatan pembelajaran misalnya untuk meningkatkan kedalaman materi peserta didik, mengidentifikasi bagian materi yang terlewat atau hilang, mengkontekstualkan pengetahuan, dan memberikan referensi komparatif dalam pembelajaran. Refleksi memungkinkan peserta didik untuk menggeneralisasi ide utama, prinsip, dan konsep abstrak dari pengalaman (Kolb, 1984). Proses refleksi meliputi pembekalan dan pembingkaian ulang dalam kaitannya dengan memperluas keyakinan dan pemahaman siswa, refleksi dapat pula digunakan untuk membantu siswa mengembangkan kesadaran, dan menggunakan petunjuk serta umpan balik untuk membimbing siswa dalam melakukan refleksi (Roskos, Vukelich, \& Risko, 2001). Tahap terakhir adalah Sharing. Pada tahap ini peserta didik melakukan Sharing menggunakan berbagai media daring yang tersedia pada E-learning. Dwiyanti (2017) menjelaskan bahwa adanya interaksi dalam pembelajaran sangat bermanfaat bagi proses belajar peserta didik. Interaksi sosial antara siswa dengan teman sebaya, guru, dan pembelajarannya merupakan salah satu contoh bentuk interkasi dalam proses pembelajaran. Lingkungan merupakan salah satu elemen utama yang memediasi perkembangan pengetahuan siswa selama proses pembelajaran. Namun, untuk memaksimalkan potensi interaksi pembelajaran siswa, guru harus memiliki kemampuan untuk mengkondisikan siswa untuk saling menjelaskan guna memfasilitasi dan mengeksplorasi penalaran dan sudut pandang, serta pertukaran ide antar siswa dalam membentuk pemahaman umum (Goos dan Reshaw, 1996; Jeong dan Chi, 2007).

Dari masing-masing tahap tersebut baik pada tahap Reading, Writing, Reflecting dan Sharing mampu memberdayakan keterampilan berpikir peserta didik. Kyriakides (2020) menyatakan bahwa kebiasaan pendidik dalam kelas akan berpengaruh besar terhadap kemampuan peserta didik dalam berpikir. Pembelajaran RWRS berpedoman pada pendekatan konstruktivistik sehingga ada bagian dimana seorang peserta didik diberi kesempatan untuk mengkonstruk pikiran mereka sendiri. Kondisi yang diciptakan dari pembelajaran RWRS ini akan membuat pembelajaran bisa berjalan lebih terarah dan kondusif terutama untuk pembelajaran daring seperti saat ini.

\section{KESIMPULAN}

Berdasarkan hasil penelitian yang dilakukan, kesimpulannya adalah bahwa ada hubungan positif antara keterampilan berpikir kritis dan keterampilan metakognitif dengan hasil belajar mahasiswa program studi pendidikan biologi. Sumbangan relatif keterampilan berpikir adalah $16,1 \%$ dan keterampilan metaognitif sebesar $83,9 \%$. Sumbangan efektif keterampilan berpikir kritis terhadap hasil belajar adalah sebesar $3,5 \%$ dan sumbangan efektif keterampilan metakognitif terhadap hasil belajar adalah $18 \%$. Jadi, total sumbangan efektif dari keterampilan berpikir kritis dan keterampilan metakognitif terhadap hasil belajar adalah $21,5 \%$, sedangkan sisanya $78,5 \%$ merupakan sumbangan yang berasal dari faktor lainnya selain keterampilan berpikir 
kritis dan keterampilan metakognitif. Persamaan regresi dari hubungan antara keterampilan berpikir kritis dan keterampilan metakognitif terhadap hasil belajar adalah $\mathrm{Y}=-16,745+0,450 \times 1+0,683 \times 2$. Keterampilan berpikir kritis dan keterampilan metakognitif telah terbukti memiliki hubungan positif dengan hasil belajar mahasiswa dimana sumbangan keterampilan metakognitif lebih tinggi terhadap hasil belajar mahasiswa. Meskipun begitu, keterampilan berpikir kritis juga memiliki andil dalam peningkatan hasil belajar mahasiswa. Oleh karena itu, diharapkan para dosen juga memperhatikan keterampilan metakognitif mahasiswa dan lebih memberdayakan keterampilan metakognitif selama proses pembelajaran.

\section{DAFTAR PUSTAKA}

Aji, R.H.S. (2020). Dampak Covid-19 pada Pendidikan di Indonesia: Sekolah, Keterampilan, dan Proses Pembelajaran. Jurnal Sosial \& Budaya Syar-i. 7 (5): 395-402. DOI: $10.15408 /$ sjsbs.v7i5.15314.

Azevedo, R. (2009). Theoretical, Conceptual, Methodological, and Instructional Issues in Research on Metacognition and Self-regulated Learning: A Discussion. Metacognition and Learning. 4 (1):87-95. doi:10.1007/s11409-009-9035-7.

Bannert, M., \& C. Mengelkamp. (2013). Scaffolding Hypermedia Learning through Metacognitive Prompts. In International Handbook of Metacognition and Learning Technologies, edited by R. Azevedo and V. Aleven, 171-186. Amsterdam, The Netherlands: Springer. doi: 10.1007/978-1-4419-5546-3_12.

Bannert, M., C. Sonnenberg, C. Mengelkamp, \& E. Pieger. (2015). Short-and Longterm Effects of Students' Self-directed Metacognitive Prompts on Navigation Behavior and Learning Performance. Computers in Human Behavior. 52: 293306. doi:10.1016/j.chb.2015.05.038.

Bartlett, J.E. (2002). Analysis of motivational orientation and learning strategies of high school business students. Bus. Educ. Forum, 56(4): 18-23.

Bransford, J. D., A. L. Brown, \& R. R. Cocking. (1999). How People Learn: Brain, Mind, Experience, and School. Washington, DC: National Academy Press.

Brown, A. L., J. D. Bransford, R. A. Ferrara, \& J. C. Campione. (1983). Learning, Remembering, and Under- Standing. In Handbook of Child Psychology, edited by J. H. Flavell and E. M. Markham, 77-166. Vol. 3. New York: Wiley.

Chang, B. (2019). Reflection in learning. Online Learning, 23(1), 95-110. doi: 10.24059/olj.v23i1.1447.

Eliasa, E.I. (2014). Increasing Values of Teamwork and Responsibility of The Students Through Games: Integrating Education Character in Lectures. Social and

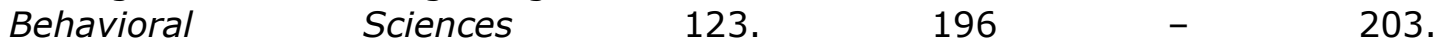
https://doi.org/10.1016/j.sbspro.2014.01.1415.

Goos, M., Galbraith, P., \& Renshaw, P. (1996). When Does Student Talk Become Collaborative Mathematical Discussion. Proceedings of the 19 th ACME Research Group of Australasia, University of Melbourne.

Greene, J. A., K. R. Dellinger, B. B. Tüysüzoglu, \& L. J. Costa. (2013). A Two-tiered Approach to Analyzing Self-regulated Learning Data to Inform the Design of Hypermedia Learning Environments. In International Handbook of Metacognition 
and Learning Technologies, edited by R. Azevedo and V. Aleven, 117-128. New York, NY: Springer

Haesol Bae \& Kyungbin Kwon (2019): Developing metacognitive skills through class activities: what makes students use metacognitive skills?, Educational Studies, DOI: $10.1080 / 03055698.2019 .1707068$

Harmer, J. (2004). How to teach writing. Essex, England: Longman, Pearson Education.

Jeong, H., \& Chi, M.T.H. (2007). Knowledge Convergence and Collaborative Learning. Instructional Science, 35(4), 287-315.

Joyce, B., Weil, M., \& Calhoun, E. (2011). Models of teaching. Boston: Pearson/Allyn and Bacon Publishers.

Kolb, D. A. (1984). Experiential learning: Experience as the source of learning and development (Vol. 1). Englewood Cliffs, NJ: Prentice-Hall.

Laberge, R. P. (2013). Teamwork in cross disciplinarity. Procedia-Social and Behavioral Sciences, 106.

Leutwyler, B., \& Maag Merki, K. (2009). School effects on students' self-regulated learning: A multivariate analysis of the relationship between individual perceptions of school processes and cognitive, metacognitive, and motivational dimensions of self-regulated learning. Journal for Educational Research Online, $1,197-223$.

Limbach, B., Waugh, W., 2010. Developing higher level thinking. Journal of Instructional Pedagogies 3, 1-9, Retrieved October 21, 2020. doi:10.1016/j.jksult.2011.01.001.

Lin, X. (2001). Designing Metacognitive Activities. Educational Technology Research and Development 49 (2): 23-40. https://rdcu.be/43C3.

Malahayati, E.N. (2015). Hubungan Keterampilan Metakognitif Dan Kemampuan Berpikir Kritis Dengan Hasil Belajar Biologi Siswa SMA Dalam Pembelajaran Problem Based Learning (PBL). Jurnal Pendidikan Sains Universitas Negeri Malang. 3 (4): 178-185. Doi 10.17977/jps.v3i4.8168.

Massi, M. P. (2001). Interactive writing in the EFL class: A repertoire of tasks. The Internet TESL Journal, 7 (6). Retrieved from http://iteslj.org/Techniques/Massi-WritingTasks.html.

Muijs, D., Kyriakides, L., van der Werf, G., Creemers, B. P. M., Timperley, H., \& Earl, L. (2014). State of the art - Teacher effectiveness and professional learning. School Effectiveness and School Improvement: An International Journal of Research. Policy and Practice, 25(2), 231-256. DOI: 10.1080/09243453.2014.885451.

Plotnikova, N. F. \& Strukov, E. N. (2019). Integration of teamwork and critical thinking skills in the process of teaching students. Cypriot Journal of Educational Sciences. 14(1), 001-010. DOI: 10.18844/cjes.v14i1.4031.

Rippen, A., Booth, C., Bowie, S., Jordan, J. (2002). A complex case: Using the case study method to explore uncertainty and ambiguity in undergraduate business 
$\begin{array}{lllll}\text { education. } & \text { Teach. } & \text { High. } & \text { Educ., } & 7(4):\end{array}$ https://doi.org/10.1080/135625102760553928.

Roskos, K., Vukelich, C., \& Risko, V. (2001). Reflection and learning to teach reading: A critical review of literacy and general teacher education studies. Journal of Literacy Research, 33(4), 595-635. doi:10.1080/10862960109548127.

Saputra, J.A. (2018). The Correlation Between Critical Thinking and Writing Achievement of The Fifth Semester Students of English Education Study Program Of UIN Raden Fatah Palembang. http://doi.org/10.5281/zenodo.1293289

Scheerens, J. (2013). The use of theory in school effectiveness research revisited. School Effectiveness and School Improvement, 24(1), 1-38. https://doi.org/10.1080/09243453.2012.691100

Scriven M, Paul R (2007). Defining critical thinking. The Critical Thinking Community: Foundation for Critical Thinking. Retrieved January 2, from http://www.criticalddnking.org/aboutCT/define criticat thinking.cfm.

Smith, V. G., \& Szymanski, A. (2013). Critical Thinking More than Test Scores. International Journal of Educational Leadership Preparation, 8, 16-25.

Tempelaar DT (2006). The role of metacognition in business education. Ind. High. Educ., 20(5): 291-297. https://doi.org/10.5367/000000006778702292

Whitebread, D., P. Coltman, D. P. Pasternak, C. Sangster, V. Grau, S. Bingham, Q. Almeqdad, \& D. Demetriou. (2009). The Development of Two Observational Tools for Assessing Metacognition and Self-regulated Learning in Young Children. Metacognition and Learning 4 (1): 63-85. doi:10.1007/s11409-008-9033-1.

Wicaksono, A.G. (2014). HubunganKeterampilan Metakognitif dan Berpikir Kritis terhadap Hasil Belajar Kognitif Siswa SMA pada Pembelajaran Biologi dengan Strategi Reciprocal Teaching. Jurnal Pendidikan Sains, 2 (2): 85-92. ISSN: 2338-9117.

Zimmerman, B. J. (2008). Investigating Self-regulation and Motivation: Historical Background, Methodological Developments, and Future Prospects. American Journal of International Research 45: 166-183. doi: $10.3102 / 0002831207312909$. 